\title{
Occurrence and antibiogram of Listeria species in raw pork, beef, and chicken meats marketed in Enugu State, Southeast Nigeria
}

\author{
Onyinye Josephine Okorie-Kanu1, Madubuike Umunna Anyanwu², Ekene Vivienne Ezenduka1, \\ Anthony Christian Mgbeahuruike ${ }^{2}$, Christian Onwuchokwe Okorie-Kanu ${ }^{3}$, Ejike Ekene Ugwuijem ${ }^{4}$, \\ Martha Nkechinyere Idogwu ${ }^{4}$, Chidiebere Ohazuruike Anyaoha ${ }^{1}$, Onyinye Lynda Majesty-Alukagberie ${ }^{1}$, \\ Roberto O. Vidal ${ }^{5}$ and Maricel Vidal ${ }^{6}$
}

\begin{abstract}
1. Department of Veterinary Public Health and Preventive Medicine, University of Nigeria, 400001 Nsukka, Enugu State Nigeria; 2. Microbiology Unit, Department of Veterinary Pathology and Microbiology, University of Nigeria, 400001 Nsukka, Enugu State Nigeria; 3. Department of Veterinary Pathology, Michael Okpara University of Agriculture, 440233 Umudike, Abia State, Nigeria; 4. Department of Microbiology, University of Nigeria, 400001 Nsukka, Enugu State, Nigeria; 5. Programa de Microbiologia y Micologia, Instituto de Ciencias Biomedicas, Facultad de Medicina, Universidad de Chile, Santiago, Chile; 6. Secretaria Regional Ministerial de Salud Region Metropolitana Santiago, Chile.

Corresponding author: Madubuike Umunna Anyanwu, e-mail: madubuike.anyanwu@unn.edu.ng Co-authors: OJO: onyinye.okoro@unn.edu.ng, EVE: ekene.ezenduka@unn.edu.ng,

ACM: anthony.mgbeahuruike@unn.edu.ng, COO: drcokoriekanu@yahoo.co.uk, EEU: ejaikitomass@gmail.com, MNI: marthaidogwudoris@gmail.com,COA: chidi.anyaoha@unn.edu.ng, OLM: onyinye.obodoechi@unn.edu.ng, ROV: rvidal@uchile.cl, MV: maricel.vidal@redsalud.gob.cl

Received: 11-10-2019, Accepted: 13-01-2020, Published online: 18-02-2020
\end{abstract}

doi: www.doi.org/10.14202/vetworld.2020.317-325 How to cite this article: Okorie-Kanu OJ, Anyanwu MU, Ezenduka EV, Mgbeahuruike AC, Okorie-Kanu CO, Ugwuijem EE, Idogwu MN, Anyaoha CO, Majesty-Alukagberie OL, Vidal RO, Vidal M (2020) Occurrence and antibiogram of Listeria species in raw pork, beef, and chicken meats marketed in Enugu State, Southeast Nigeria, Veterinary World, 13(2): 317-325.

\begin{abstract}
Aim: This study was undertaken to isolate Listeria (L.) species from raw meats sold in markets in Enugu State, Southeast Nigeria, and to determine the antibacterial resistance profile.

Materials and Methods: Twenty-five grams of beef $(n=144)$, chicken meat $(n=144)$, and pork ( $n=144)$ were collected randomly from supermarkets and general markets in Enugu State. Isolation of Listeria was done using half and full Fraser broths, and polymyxin acriflavine lithium chloride ceftazidime aesculin mannitol agar. Identification of isolates was done using an analytical profile index kit specific for Listeria. Confirmation of the genus Listeria was done by a polymerase chain reaction. The resistance of the isolates was determined using the disk diffusion method.
\end{abstract}

Results: Listeria was isolated from 39/144 (27.1\%) chicken meat, 19/144 (13.2\%) pork, and 66/144 (45.8\%) beef samples cultured. Listeria innocua was the predominant species in chicken meat (52.6\%) and beef (81.8\%) samples. Listeria grayi, Listeria welshimeri, and Listeria ivanovii were also isolated from the beef and chicken meat samples. More than $65 \%$ of the isolates were resistant to penicillin, rifampicin, ciprofloxacin, sulfamethoxazole-trimethoprim, and cephalothin. All the isolates from beef and pork samples and $23(92 \%)$ from chicken meat samples, were resistant to $\geq 3$ classes of antibacterial agents. Mean multiple antibiotic resistance index (MARI) was 0.77 (range=0.42-1.00), 0.58 (range=0.25-0.83), and 0.79 (range $=0.58-0.92)$ for the isolates from beef, chicken meat, and pork samples, respectively. All the isolates had MARI $>0.2$.

Conclusion: Multidrug-resistant Listeria strains contaminate raw beef, pork, and chicken meats marketed in Enugu State, Southeast Nigeria.

Keywords: antibacterial resistance, beef, chicken meat, Listeria species, pork.

\section{Introduction}

Listeria species are Gram-positive rods constituting part of normal commensal flora in the gut of humans and animals [1]. Due to their virulence attributes (biofilm formation, invasion and survival in host's phagocytic cells, and so on), Listeria species are facultatively pathogenic and they are associated with zoonotic foodborne infections (generally termed listeriosis) worldwide [2]. The economic and health burden

Copyright: Okorie-Kanu, et al. Open Access. This article is distributed under the terms of the Creative Commons Attribution 4.0 International License (http://creativecommons.org/licenses/ by/4.0/), which permits unrestricted use, distribution, and reproduction in any medium, provided you give appropriate credit to the original author(s) and the source, provide a link to the Creative Commons license, and indicate if changes were made. The Creative Commons Public Domain Dedication waiver (http:// creativecommons.org/publicdomain/zero/1.0/) applies to the data made available in this article, unless otherwise stated. of listeriosis is outrageous. In the United States alone, the annual cost of foodborne listeriosis was estimated at US\$2.3-22 billion while effective control of this disease potentially saves US\$0.01-2 billion/year [3]. Reports of cases of Listeria infections concentrated in developed countries whereas cases in developing nations were unreported and underestimated [4]. However, the recent outbreak of listeriosis in South Africa (2017-2018) which accounted for 27\% mortality (World Health Organization [WHO], 2018) [5], rekindled the interest in occurrence of Listeria species especially the antibacterial-resistant (ABR) strains, in foods of animal origin particularly in developing countries [2,5]. The WHO listed listeriosis as one of the notifiable diseases and issued a call for intensified surveillance of Listeria in foods of animal origin [5]. Because Listeria species are ubiquitous and highly 
adaptive tolerating adverse environmental conditions (such as low $\mathrm{pH}$, high salinity and bile concentration, oxidative stress, carbon starvation, and so on), they easily contaminate slaughterhouse environment, especially where unhygienic slaughtering techniques are employed [6]. It is established that cross-contamination of meat and associated products at slaughterhouse, packaging and/or retailing stages, constitute putative risks for infection of individuals who make direct/indirect contact and/or consume these meat products [7]. Among the 18 currently known Listeria species [8], only Listeria monocytogenes and Listeria ivanovii were thought to be pathogenic being incriminated in several invasive diseases in humans and animals especially in immunocompromised individuals $[6,9]$. Today, other Listeria species such as Listeria welshimeri and Listeria innocua are increasingly isolated from diseased individuals [10,11].

Before now, infections caused by Listeria species were not difficult to treat because these organisms were considered susceptible to a wide variety of antibacterials [2,12]. But recently, the treatment of these infections has become increasingly difficult due to antibacterial resistance (particularly multidrug resistance [MDR]) [2,6]. Consequently, it is necessary to continually monitor the occurrence and antibacterial susceptibility of Listeria species from various settings [6]. Inappropriate use of antibacterials in humans and animals is the major cause of acquired resistance in Listeria species [2,6]. In Nigeria, the use of antimicrobials in the management of meat-yielding animals is uncontrolled; thus, veterinarians and non-professionals without veterinary supervision habitually use different types of antibacterial for prophylaxis and treatment of infections in these animals [13]. Thus, food animals (chicken, cattle, and pigs) slaughtered in Nigeria may be colonized by ABR Listeria spp. Meat derived from animals colonized by ABR Listeria can easily get contaminated with these organisms especially in slaughterhouses (as in Nigeria) where unhygienic slaughtering methods are employed and/or personal hygiene of the slaughterhouse workers are poor. Presence of ABR Listeria strains in meat is of public health importance because individuals who make direct or indirect contact with and/or consume these meats and associated products could acquire these organisms (and transfer them to their households/ public) which are capable of transferring resistance genes by horizontal transfer to other bacteria in the gut of infected individuals. Compromise of subsequent antibacterial therapy in these individuals is a possible outcome and this has huge effects on public health.

In the available literature, studies from several countries [7,9,14-19] reported the occurrence and antimicrobial susceptibility of Listeria isolates from meats. In Nigeria, there are scanty reports in this regard, and these include studies in North-central [20,21], South-south [22-24], and South-west [4] regions of the country. The occurrence of ABR Listeria strains in foods of animal origin in Southeast Nigeria has remained uninvestigated. Moreover, identification of Listeria in the previous Nigerian studies was based on traditional biochemical tests which are not as reliable as genotypic methods. Thus, these studies might have underestimated or overrated the occurrence of Listeria in the meat samples.

This study aimed to isolate Listeria species from raw beef, pork, and chicken meats sold at markets in Enugu State Southeast Nigeria and to determine antimicrobial susceptibility profile of the isolates.

\section{Materials and Methods}

\section{Ethical approval}

Ethical approval was not necessary for this study. However, approval to conduct the study was obtained from the Department of Veterinary Public Health and Preventive Medicine, University of Nigeria.

\section{Study area}

This study was conducted in Enugu State, Southeast Nigeria. The state comprised three senatorial/agricultural zones and 17 local government areas. Enugu State is located at latitudes $5^{\circ} 56^{\prime}$ North and $7^{\circ} 55^{\prime}$ North and longitudes $6^{\circ} 53^{\prime}$ East and $7^{\circ} 55^{\prime}$ East. Beef, pork, and chicken meats constitute the major animal protein consumed by the Enugu State population.

\section{Sampling}

Between January 2018 and June 2018, three general markets (Ogige market in Nsukka, Abakpa, and Ogbete main markets in Enugu) and three supermarkets (all in Enugu metropolis) in Enugu State Southeast Nigeria, were visited 6 times each at weekly interval. In the general markets, potential meat buyers, as well as the butchers, frequently handle the meat while untrained personnel process and package meat for the supermarkets. A $25 \mathrm{~g}$ of chicken meat $(\mathrm{n}=144)$, beef $(n=144)$, and pork $(n=144)$ samples were collected and transported with ice packs to the laboratory of the Department of Veterinary Public Health and Preventive Medicine, University of Nigeria and processed on the day of collection.

\section{Isolation of Listeria species}

This was done following the International Organization of Standardization's 11290-1 guidelines [25]. Briefly, each sample was aseptically transferred into a sterile bag containing $225 \mathrm{~mL}$ pre-enrichment half-Fraser broth (HFB) (Oxoid, Basingstoke UK) with half-Fraser supplement, pulverized/homogenized using a stomacher for $1 \mathrm{~min}$, and incubated at $30^{\circ} \mathrm{C}$ for $24 \mathrm{~h}$ in ambient air. Then, $0.1 \mathrm{ml}$ of the HFB culture was inoculated into $10 \mathrm{ml}$ enrichment full-Fraser broth (FFB) (Oxoid, Basingstoke UK) with full-Fraser supplement, and incubated at $37^{\circ} \mathrm{C}$ for $48 \mathrm{~h}$ in ambient air. A loopful of the FFB culture was inoculated on polymyxin acriflavine lithium chloride ceftazidime aesculin mannitol (PALCAM) agar (Oxoid, Basingstoke UK) with the supplement, and incubated at $37^{\circ} \mathrm{C}$ for $48 \mathrm{~h}$. Suspected Listeria isolates 
(small-sized grayish-green colonies) were purified by sub-culturing/inoculating on fresh PALCAM agar with the supplement, and incubated at $37^{\circ} \mathrm{C}$ for $48 \mathrm{~h}$. Pure cultures of the isolates were then inoculated on PALCAM agar slants with the supplement, incubated at $37^{\circ} \mathrm{C}$ for $48 \mathrm{~h}$, and stored in a refrigerator at $4^{\circ} \mathrm{C}$ as stock cultures until needed for further analysis.

\section{Speciation of Listeria isolates}

Phenotypic characterization of the isolates to species level was done by subjecting them to Gram staining and various biochemical tests such as catalase and hemolysis tests, as well as arylamidase (3,3'-diindolylmethane test), esculin hydrolysis, presence of $\alpha$-mannosidase, and fermentation of D-arabitol, D-xylose, L-rhamnose, $\alpha$-methyl-D-glucoside, D-ribose, glucose-1-phosphate, and D-tagatose using analytic profile index (API) Listeria kit (Biomerieux, France) as per the manufacturer's instructions.

\section{Molecular confirmation/identification of the genus Listeria}

Bacterial cultures were sub-cultured on PALCAM agar with supplement and incubated accordingly as above. Colonies of the isolates were inoculated into brain heart infusion broth (Oxoid, Basingstoke UK), and incubated at $37^{\circ} \mathrm{C}$ for $24 \mathrm{~h}$. DNA of the isolates was extracted using bacterial DNA extraction and purification kit (Promega, USA) following the manufacturer's directions. Using previously described protocols [18,26], DNA fragments of the Listeria specific prs gene of $370 \mathrm{bp}$ were amplified by polymerase chain reaction (PCR) using prsF: 5'-GCTGAAGAGAGATTGCGAAAAGAAG-3' and prsR:5'-CAAAGAAACCTTGGATTTGCGG-3'[26]. The PCR mixture was prepared in a total volume of $50 \mu$ l containing 5 of $10 \times$ buffer, $1.5 \mathrm{mMMgCl}_{2}, 250 \mu \mathrm{M}$ each of the four dNTPs (Fermentes, Lithuania), $1.25 \mathrm{U}$ of Taq DNA (Fermentes, Lithuania), $0.5 \mu \mathrm{M}$ of each primer (IDT, USA), and $5 \mu \mathrm{L}$ of template DNA [18]. The amplification was performed with an initial denaturation step at $94^{\circ} \mathrm{C}$ for $3 \mathrm{~min} ; 35$ cycles of $94^{\circ} \mathrm{C}$ for $0.40 \mathrm{~min}, 53^{\circ} \mathrm{C}$ for $1.15 \mathrm{~min}$, and $72^{\circ} \mathrm{C}$ for $1.15 \mathrm{~min}$; and one final cycle of $72^{\circ} \mathrm{C}$ for $7 \mathrm{~min}$ in a thermocycler (Eppendorf Mastercycler, Germany) [26]. Thereafter, $5 \mu \mathrm{l}$ of the reaction mixture was mixed with $3 \mu \mathrm{l}$ of loading buffer and separated on a $2 \%$ agarose gel in a TBE buffer ( $90 \mathrm{mM}$ Trizma base, $90 \mathrm{mM}$ boric acid, 2 mM EDTA, pH 8.3) [26]. The PCR product was visualized by ethidium bromide staining.

\section{Antibacterial susceptibility testing (AST)}

Antibacterial susceptibility of 33,25 , and 10 Listeria isolates from beef, chicken meat, and pork samples, respectively, was determined by the disk diffusion method [27], using disks impregnated with 12 different antibacterial agents belonging to nine classes: $\beta$-lactam - penicillin (PEN, 10 units), amoxicillin (AMX, $10 \mu \mathrm{g}$ ), ampicillin (AMP, $2 \mu \mathrm{g}$ ), and cephalothin (CEF, $30 \mu \mathrm{g})$, nitroheterocyclics - nitrofurantoin (NIT, $300 \mu \mathrm{g}$ ), ansamycins - rifampicin (RIF, $5 \mu \mathrm{g}$ ), aminoglycosides - gentamicin (GEN, $10 \mu \mathrm{g}$ ), glycopeptides - vancomycin (VAN, $30 \mu \mathrm{g})$, tetracycline $(30 \mu \mathrm{g})$, fluoroquinolones - ciprofloxacin (CIP, $5 \mu \mathrm{g})$, macrolides - erythromycin (ERY, $15 \mu \mathrm{g}$ ), and folate pathway inhibitors - sulfamethoxazole-trimethoprim (SXT, $25 \mu \mathrm{g})$. L. monocytogenes American Type Culture Collection (ATCC) 13932, Streptococcus pneumoniae ATCC 49619, and Staphylococcus aureus ATCC 29213, were used as reference strains. Results of the AST were interpreted according to the European Committee on Antimicrobial Susceptibility Testing [28] recommendations for L. monocytogenes, and Clinical and Laboratory Standards Institute [29] guidelines for $S$. pneumoniae (for the result of CEF) and staphylococci (for the results of PEN, AMX, NIT, RIF, VAN, TET, GEN, and CIP), respectively. Intermediately-susceptible isolates were classified as resistant. The multiple antibiotic resistance index (MARI) of the isolates was determined using the formula $a / b$ where " $a$ " is the number of antibacterial agents to which an isolate was resistant and "b" is the number of antibacterial agents to which an isolate was exposed [30]. Mean MARI was calculated as the ratio of total MARI and the total number of resistant isolates. An isolate resistant to $\geq 3$ classes of antibiotics was considered multidrug-resistant [31].

\section{Statistical analysis}

The frequencies of occurrence of Listeria spp. and resistance of the isolates were entered into Microsoft Excel version 2010 and their percentages and confidence intervals (CI) calculated.

\section{Results}

Occurrence of Listeria species in raw meat samples Listeria was isolated from 39/144(27.1\%) chicken meat, 19/144 (13.2\%) pork, and 66/144 (45.8\%) beef samples cultured, respectively (Table-1). Of the 39 isolates from chicken meat, 31 (79.5\%, 95\% CI 66.8-92.2) were L. innocua, three (7.7\%, 95\% CI 0-16.1) each were Listeria grayi and L. ivanovii while 2 (5.1\%, 95\% CI 0-12.0) were L. welshimeri. The L. welshimeri and one L. innocua strain were recovered from the same sample. Among the 19 isolates from pork samples, nine (47.4\%, 95\% CI 31.7-63.1) were L. innocua whereas ten $(52.6 \%, 95 \%$ CI 36.9-68.3) were Listeria species. Fifty-four (81.8\%, 95\% CI 69.7-93.9) of the 66 isolates from beef samples were L. innocua while four (6.1\%, 95\% CI 0-13.6) each were L. grayi, L. welshimeri, and L. ivanovii. Two of the L. grayi isolates and one L. innocua strain were obtained from two samples; all the L. welshimeri strains were isolated together with L. innocua in four samples whereas two L. ivanovii and two L. grayi strains were recovered from two different samples.

\section{Antibacterial susceptibility of Listeria isolates from raw meats}

Among 33 isolates from beef, 31 (93.9\%, 95\% CI 85.9-100) were resistant to CEF, $30(90.9 \%, 95 \%$ CI 87.7-94.1) to SXT and RIF, 29 (87.9\%, 95\% CI 
76.8-99.0) to VAN and ERY, $26.9(78.8 \%, 95 \%$ CI 64.9-92.7) to CIP, $22(66.7 \%, 95 \%$ CI $39.1-94.3)$ to TET and GEN, $19(57.6 \%, 95 \%$ CI $40.7-74.5)$ to AMP, $18(54.5 \%, 95 \%$ CI 37.6-71.4) to NIT, and 16 (48.5\%, 95\% CI 31.4-65.6) to AMX (Table-2). Of the ten isolates from pork, all (95\% CI 100) were resistant to CEF, CIP, and SXT, nine $(90 \%, 95 \%$ CI $71.4-100)$ to RIF, eight $(80 \%, 95 \%$ CI $55.2-100)$ to ERY, seven $(70 \%, 95 \%$ CI 41.6-98.4) to NIT, VAN, and TET, six $(60 \%, 95 \%$ CI $29.7-90.3)$ to GEN, and five $(50 \%, 95 \%$ CI $19.1-80.9)$ to AMX and AMP. Out of 25 isolates from chicken meat, 24 (96\%, 95\% CI 88.4-100) were resistant to CEF, 18 (72\%, 95\% CI 54.4-89.6) to SXT and RIF, 15 (60\%, 95\% CI 40.8$79.2)$ to CIP, $14(56 \%, 95 \%$ CI $36.5-56.0)$ to ERY, $11(44 \%, 95 \%$ CI $24.5-63.5)$ to AMP, ten $(40 \%, 95 \%$ CI $20.8-51.2)$ to VAN and TET, nine $(36 \%, 95 \%$ CI 17.2-54.8) to GEN, six $(24 \%, 95 \%$ CI $37.3-40.7)$ to NIT, and five $(20 \%, 95 \% 4.3-35.7)$ to AMX. All the isolates were resistant to PEN. All the isolates from beef (33), pork (10), and $23(92 \%)$ from chicken meat samples were resistant to $\geq 3$ classes of antibacterial agents (Tables-3-5). Twenty-two, 21 and eight multiple ABR patterns (resistance to two or more antibacterial agents) were exhibited by isolates from beef, chicken meat, and pork, respectively. The resistance patterns PEN, CEF, AMX, NIT, VAN, TET, GEN, ERY, CIP, SXT, and RIF ( $\mathrm{n}=4)$; PEN, CEF, VAN, GEN, CIP, AMP, SXT, PEN, CEF, TET, ERY, CIP, SXT, RIF, PEN, CEF, NIT, TET, ERY, CIP, SXT, RIF and PEN, CEF, AMX, NIT, VAN, GEN, ERY, CIP, SXT, and RIF ( $\mathrm{n}=2$ for each); and PEN, CEF, AMX, NIT, VAN, TET, GEN, ERY, CIP, SXT, and RIF $(n=2)$ were predominant among isolates from beef, chicken meat, and pork, respectively. Mean MARI was 0.77 $($ range $=0.42-1.00), 0.58$ (range $=0.25-0.83)$, and 0.79 (range $=0.58-0.92$ ) for beef, chicken meat, and pork isolates, respectively. All the isolates had MARI >0.2.

\section{Discussion}

In this study, Listeria was isolated from $27.1 \%$ chicken meat, $13.2 \%$ pork, and $45.8 \%$ beef samples suggesting that in Enugu State Nigeria, beef is more contaminated with the organisms than chicken meat and pork. This finding may be due to the larger surface area of cattle carcasses compared with meat carcass surface area of the other sampled animal types; therefore, the beef samples might have been contaminated more than the other meat-type samples. Possible sources of these organisms in the sampled meats include fecal contamination during slaughter/processing by endogenous Listeria, cross-contamination from slaughterhouse environment (as Nigerian slaughterhouses are usually in poor sanitary conditions), fomites (such as knives, wheelbarrow, meat-transport vehicles, meat display tables, and cloths used for cleaning tables), water used for washing carcasses and meat display tables, flies colonized with Listeria, and/or cloths/hands of butchers, meat-retailers, and/or buyers [15,23]. Listeria species are known to cross-contaminate meat samples from

Table-1: Distribution of Listeria species in raw meats in Enugu State Southeast Nigeria.

\begin{tabular}{|c|c|c|c|c|c|c|c|}
\hline \multirow[t]{2}{*}{ Sample type } & \multirow{2}{*}{$\begin{array}{c}\text { Number of } \\
\text { samples cultured }\end{array}$} & \multicolumn{5}{|c|}{ Number (\%) of isolates, $95 \%$ CI } & \multirow[t]{2}{*}{ Total (\%) } \\
\hline & & L. innocua & L. ivanovii & L. grayi & L. welshimeri & Listeria species & \\
\hline Chicken meat & 144 & $\begin{array}{l}31(79.5) \\
66.8-92.2\end{array}$ & $\begin{array}{c}3(7.7) \\
0-16.1\end{array}$ & $\begin{array}{c}3(7.7) \\
0-16.1\end{array}$ & $\begin{array}{c}2(5.1) \\
0-12.0\end{array}$ & $0(0.0)$ & $39(27.1)$ \\
\hline Pork & 144 & $\begin{array}{c}9(47.4) \\
31.7-63.1\end{array}$ & $0(0.0)$ & $0(0.0)$ & $0(0.0)$ & $\begin{array}{l}10(52.6) \\
36.9-68.3\end{array}$ & $19(13.2)$ \\
\hline Beef & 144 & $\begin{array}{l}54(81.8) \\
69.7-93.9\end{array}$ & $\begin{array}{c}4(6.1) \\
0-13.6\end{array}$ & $\begin{array}{c}4(6.1) \\
0-13.6\end{array}$ & $\begin{array}{c}4(6.1) \\
0-13.6\end{array}$ & $0(0.0)$ & $66(45.8)$ \\
\hline
\end{tabular}

L=Listeria, $\mathrm{CI}=$ Confidence Interval

Table-2: Antibacterial susceptibility profile of Listeria isolates from raw meats marketed in Enugu State Southeast Nigeria.

\begin{tabular}{|c|c|c|c|c|}
\hline \multirow[t]{2}{*}{ Antibacterial class } & \multirow{2}{*}{$\begin{array}{l}\text { Antibacterial agent } \\
\text { (Concentration) }\end{array}$} & \multicolumn{3}{|c|}{ Number (\%) of resistant isolates, $95 \%$ CI } \\
\hline & & Beef $(n=33)$ & Chicken meat $(n=25)$ & Pork $(n=10)$ \\
\hline$\beta$-lactam & $\begin{array}{l}\text { Penicillin (10 units) } \\
\text { Cephalothin }(30 \mu \mathrm{g}) \\
\text { Amoxicillin }(10 \mu \mathrm{g}) \\
\text { Ampicillin }(2 \mu \mathrm{g})\end{array}$ & $\begin{array}{c}33(100.0), 100 \\
31(93.9), 85.9-100 \\
16(48.5), 31.4-65.6 \\
19(57.6), 40.7-74.5\end{array}$ & $\begin{array}{c}25(100.0), 100 \\
24(96.0), 88.4-100 \\
5(20.0), 4.3-35.7 \\
11(44.0), 24.5-63.5\end{array}$ & $\begin{array}{c}10(100.0), 100 \\
10(100.0), 100 \\
5(50.0), 19.1-80.9 \\
5(50.0), 19.1-80.9\end{array}$ \\
\hline Nitroheterocyclics & Nitrofurantoin $(30 \mu \mathrm{g})$ & $18(54.5), 37.6-71.4$ & $6(24.0), 37.3-40.7$ & $7(70.0), 41.6-98.4$ \\
\hline Glycopeptides & Vancomycin $(30 \mu \mathrm{g})$ & 29 (87.9), 76.8-99.0 & $10(40.0), 20.8-51.2$ & $7(70.0), 41.6-98.4$ \\
\hline Tetracyclines & Tetracycline $(30 \mu \mathrm{g})$ & $22(66.7), 39.1-94.3$ & $10(40.0), 20.8-51.2$ & $7(70.0), 41.6-98.4$ \\
\hline Aminoglycosides & Gentamicin $(10 \mu \mathrm{g})$ & $22(66.7), 50.7-82.7$ & $9(36.0), 17.2-54.8$ & $6(60.0), 29.7-90.3$ \\
\hline Macrolides & Gentamicin $(10 \mu \mathrm{g})$ & 29 (87.9), 76.8-99.0 & $14(56.0), 36.5-56.0$ & $8(80.0), 55.2-100$ \\
\hline Fluoroquinolones & Ciprofloxacin $(5 \mu \mathrm{g})$ & $26(78.8), 64.9-92.7$ & $15(60.0), 40.8-79.2$ & $10(100.0), 100$ \\
\hline Ansamycins & Rifampicin $(5 \mu \mathrm{g})$ & 30 (90.9), 87.7-94.1 & $18(72.0), 54.4-89.6$ & $9(90.0), 71.4-100$ \\
\hline Folate inhibitors & $\begin{array}{l}\text { SUlphamethoxazole- } \\
\text { trimethoprim }(5 \mu \mathrm{g})\end{array}$ & $30(90.9), 87.7-94.1$ & $18(72.0), 54.4-89.6$ & $10(100.0), 100$ \\
\hline
\end{tabular}

$\mathrm{CI}=$ Confidence Interval 
Table-3: Multiple antibacterial resistance patterns and indices of 33 Listeria isolates from raw beef marketed in Enugu State Southeast Nigeria.

\begin{tabular}{|c|c|c|c|}
\hline $\begin{array}{l}\text { Number of } \\
\text { antibacterial class }\end{array}$ & Resistance pattern (Number of isolates) & $\begin{array}{l}\text { Total number } \\
\text { of isolates }(\%)\end{array}$ & $\begin{array}{l}\text { MARI } \\
\text { (Total) }\end{array}$ \\
\hline 3 & PEN, CEF, VAN, AMP, RIF (1) & $33(100)$ & $0.42(0.42)$ \\
\hline \multirow[t]{2}{*}{4} & $\begin{array}{l}\text { PEN, VAN, ERY, AMP, SXT (1) } \\
\text { PEN, CEF, NIT, VAN, AMP (1) }\end{array}$ & & $0.42(0.84)$ \\
\hline & PEN, CEF, AMX, VAN, CIP, AMP, RIF (1) & & $0.58(0.58)$ \\
\hline \multirow[t]{6}{*}{6} & PEN, CEF, AMX, TET, ERY, CIP, SXT, RIF (1) & & $0.67(0.67)$ \\
\hline & PEN, CEF, NIT, VAN, GEN, SXT, RIF (1) & & $0.58(0.58)$ \\
\hline & PEN, VAN, TET, ERY, SXT, RIF (1) & & $0.50(0.50)$ \\
\hline & PEN, CEF, AMX, TET, GEN, ERY, CIP, AMP, SXT (1) & & $0.75(0.75)$ \\
\hline & PEN, CEF, VAN, TET, ERY, AMP, SXT, RIF (1) & & $0.67(1.34)$ \\
\hline & PEN, CEF, AMX, GEN, ERY, CIP, SXT, RIF (1) & & \\
\hline \multirow[t]{4}{*}{7} & PEN, CEF, AMX, NIT, VAN, ERY, CIP, AMP, SXT, RIF (1) & & $0.83(0.83)$ \\
\hline & PEN, CEF, AMX, TET, GEN, ERY, CIP, SXT, RIF (1) & & $0.75(1.50)$ \\
\hline & PEN, CEF, VAN, TET, ERY, CIP, AMP, SXT, RIF (1) & & \\
\hline & PEN, CEF, VAN, GEN, ERY, CIP, SXT, RIF (1) & & $0.67(0.67)$ \\
\hline \multirow[t]{5}{*}{8} & PEN, CEF, VAN, TET, GEN, ERY, CIP, AMP, SXT, RIF (3) & & $0.83(6.64)$ \\
\hline & PEN, CEF, NIT, VAN, TET, ERY, CIP, AMP, SXT, RIF (2) & & \\
\hline & PEN, CEF, AMX, NIT, VAN, TET, GEN, ERY, SXT, RIF (1) & & \\
\hline & PEN, CEF, AMX, NIT, VAN, GEN, ERY, CIP, SXT, RIF (2) & & \\
\hline & PEN, CEF, NIT, VAN, GEN, ERY, CIP, SXT, RIF (1) & & $0.75(0.75)$ \\
\hline \multirow[t]{3}{*}{9} & PEN, CEF, NIT, VAN, TET, GEN, ERY, CIP, AMP, SXT, RIF (3) & & $0.92(6.44)$ \\
\hline & PEN, CEF, AMX, NIT, VAN, TET, GEN, ERY, CIP, SXT, RIF (4) & & \\
\hline & PEN, CEF, AMX, NIT, VAN, TET, GEN, ERY, CIP, AMP, SXT, RIF (3) & & $1.00(3.00)$ \\
\hline
\end{tabular}

MARI = Multiple antibacterial resistance index, $\mathrm{PEN}=$ Penicillin, $\mathrm{CEF}=$ Cephalothin, $\mathrm{AMX}=\mathrm{Amoxicillin}$, NIT=Nitrofurantoin, $\mathrm{VAN}=$ Vancomycin, TET=Tetracycline, GEN=Gentamicin, ERY=Erythromycin, CIP=Ciprofloxacin, AMP=Ampicillin, SXT=Sulfamethoxazole-trimethoprim, RIF=Rifampicin

Table-4: Multiple antibacterial resistance patterns and indices of 25 Listeria isolates from raw chicken meats marketed in Enugu State Southeast Nigeria.

\begin{tabular}{|c|c|c|c|}
\hline $\begin{array}{l}\text { Number of } \\
\text { antibacterial class }\end{array}$ & Resistance pattern (Number of isolates) & $\begin{array}{l}\text { Total number of } \\
\text { isolates }(\%)\end{array}$ & $\begin{array}{l}\text { MARI } \\
\text { (Total) }\end{array}$ \\
\hline 1 & PEN, CEF, AMP (1) & $1(4.0)$ & $0.25(0.25)$ \\
\hline 2 & PEN, CEF, AMP, RIF (1) & $1(4.0)$ & $0.33(0.33)$ \\
\hline \multirow[t]{2}{*}{3} & PEN, CEF, AMP, SXT, RIF (1) & $23(92)$ & $0.42(1.68)$ \\
\hline & PEN, CEF, VAN, CIP, AMP (1) & & \\
\hline \multirow[t]{4}{*}{4} & PEN, VAN, TET, AMP, RIF (1) & & \\
\hline & PEN, CEF, VAN, AMP, SXT (1) & & \\
\hline & PEN, CEF, ERY, AMP, SXT, RIF (1) & & $0.50(2.00)$ \\
\hline & PEN, CEF, NIT, CIP, AMP, RIF (1) & & \\
\hline \multirow[t]{3}{*}{5} & PEN, CEF, TET, ERY, SXT, RIF (1) & & \\
\hline & PEN, CEF, TET, CIP, SXT, RIF (1) & & \\
\hline & PEN, CEF, VAN, GEN, CIP, AMP, SXT (2) & & $0.58(1.16)$ \\
\hline \multirow[t]{4}{*}{6} & PEN, CEF, AMX, VAN, GEN, ERY, SXT, RIF (1) & & $0.67(0.67)$ \\
\hline & PEN, CEF, TET, ERY, CIP, SXT, RIF (2) & & $0.58(1.74)$ \\
\hline & PEN, CEF, GEN, ERY, CIP, SXT, RIF (1) & & \\
\hline & PEN, CEF, AMX, TET, ERY, CIP, SXT, RIF (1) & & $0.67(3.35)$ \\
\hline \multirow[t]{4}{*}{7} & PEN, CEF, NIT, TET, ERY, CIP, SXT, RIF (2) & & \\
\hline & PEN, CEF, NIT, TET, GEN, ERY, CIP, SXT (1) & & \\
\hline & PEN, CEF, VAN, GEN, ERY, CIP, SXT, RIF (1) & & \\
\hline & PEN, CEF, AMX, NIT, TET, ERY, CIP, AMP, SXT, RIF (1) & & $0.83(0.83)$ \\
\hline \multirow[t]{2}{*}{8} & PEN, CEF, NIT, VAN, GEN, ERY, CIP, SXT, RIF (1) & & $0.75(0.75)$ \\
\hline & PEN, CEF, AMX, NIT, VAN, GEN, ERY, CIP, SXT, RIF (2) & & $0.83(1.66)$ \\
\hline
\end{tabular}

MARI=Multiple antibiotic resistance index, PEN=Penicillin, $C E F=$ Cephalothin, $A M X=$ Amoxicillin, NIT=Nitrofurantoin, VAN=Vancomycin, TET=Tetracycline, GEN=Gentamicin, ERY=Erythromycin, CIP=Ciprofloxacin, AMP=Ampicillin, SXT=Sulfamethoxazole-trimethoprim, RIF=Rifampicin

environmental contact surfaces due to their ability to attach to these surfaces using peritrichous flagella and to form biofilm [15].

The $27.1 \%$ occurrence in chicken meat in this study is higher than $6.67 \%$ and $21.6 \%$ occurrence of Listeria spp. in 60 each of randomly-selected raw and frozen chicken meat samples reported in Plateau State,
North-central Nigeria, respectively [20]. However, it is lower than $40 \%, 47.5 \%, 44 \%$, and $50 \%$ occurrence of Listeria in 200 fresh chicken carcasses reported in Iran [32], 160 fresh broiler chicken meat samples reported in Jordan [33], 25 frozen raw chicken fillets recorded in Egypt [15], and ten raw chicken meats observed in Saudi Arabia [19], respectively. In 
Table-5: Multiple antibacterial resistance patterns and indices of 10 Listeria isolates from raw pork marketed in Enugu State Southeast Nigeria.

\begin{tabular}{|c|c|c|c|}
\hline $\begin{array}{l}\text { Number of } \\
\text { antibacterial class }\end{array}$ & Resistance pattern (Number of isolates) & $\begin{array}{l}\text { Total number of } \\
\text { isolates }(\%)\end{array}$ & $\begin{array}{l}\text { MARI } \\
\text { (Total) }\end{array}$ \\
\hline 5 & PEN, CEF, AMX, ERY, CIP, SXT, RIF (1) & $10(100)$ & $0.58(0.58)$ \\
\hline 6 & $\begin{array}{l}\text { PEN, CEF, NIT, VAN, CIP, AMP, SXT, RIF (1) } \\
\text { PEN, CEF, NIT, VAN, TET, CIP, AMP, SXT (1) }\end{array}$ & & $0.67(1.34)$ \\
\hline 7 & $\begin{array}{l}\text { PEN, CEF, NIT, TET, ERY, CIP, AMP, SXT, RIF (1) } \\
\text { PEN, CEF, NIT, GEN, ERY, CIP, AMP, SXT, RIF (1) }\end{array}$ & & $0.75(2.25)$ \\
\hline 8 & $\begin{array}{l}\text { PEN, CEF, VAN, TET, GEN, ERY, CIP, SXT, RIF (1) } \\
\text { PEN, CEF, AMX, VAN, TET, GEN, ERY, CIP, AMP, SXT, RIF (1) }\end{array}$ & & $0.92(3.68)$ \\
\hline
\end{tabular}

MARI = Multiple antibiotic resistance index, PEN=Penicillin, CEF=Cephalothin, AMX=Amoxicillin, NIT=Nitrofurantoin, VAN=Vancomycin, TET=Tetracycline, GEN=Gentamicin, ERY=Erythromycin, CIP=Ciprofloxacin, AMP=Ampicillin, SXT=Sulfamethoxazole-trimethoprim, RIF=Rifampicin

Korea, Arak, and Ardic [18] reported 51.66\% occurrence of Listeria in 115 randomly-selected fresh turkey meat samples while $33.3 \%$ occurrence of Listeria was reported in 401 samples of poultry products in Iran [17].

The $45.8 \%$ occurrence in beef samples in this study is higher than $42.1 \%$ and $2.1 \%$ occurrence of Listeria in 50 randomly-selected raw beef samples reported in Rivers State, South-south Nigeria [23] and raw beef carcasses in India [34], respectively. However, it is lower than $52.78 \%$ occurrence of Listeria in 36 randomly-selected raw beef samples reported in Rivers State, South-south Nigeria [22]. It is also lower than $50 \%$ occurrence of Listeria in ten raw beef samples reported in Saudi Arabia [19]. A lower occurrence (13.2\%) was recorded in raw pork samples in this study compared with $22 \%$ occurrence of Listeria in 50 pork samples reported by Odu and Okonko [23]. Other previous studies reported a $21.4-58.7 \%$ occurrence of Listeria in various types of meat samples $[7,9,14,16,19]$. The variation in the results is related to differences in the rate of meat carcass contamination, isolation, and identification methodologies. In the hereby experiment, the isolates were identified to genus level using PCR considered the "gold standard" for identification of Listeria which is difficult to be accurately identified by only phenotypic methods used in some of the previous studies [35]. Therefore, those studies, including the Nigerian reports, in which traditional phenotypic methods were solely used for the identification of Listeria, might have deemphasized or overestimated the occurrence of Listeria in the meat samples [18]. Nevertheless, similar to the findings of the previous studies on raw meat samples in Nigeria $[20,22,23]$ and elsewhere [14-17,33,36], this study identified various Listeria species, including L. ivanovii, L. innocua, L. welshimeri, and L. grayi and unidentified Listeria species suggesting that diverse Listeria species contaminate retailed/marketed meats in Nigeria. The unidentified Listeria isolates in this study could belong to the remaining 14 of the currently known 18 Listeria spp. $[1,8]$ or they may be species that are unidentifiable with the Listeria specific API kit employed in this experiment. Although L. monocytogenes (considered the most pathogenic Listeria species) was not identified in this work, the other identified species have been associated with invasive diseases (such as bacteremia) responsible for morbidity and mortality in humans and animals $[10,11,37,38]$ and therefore calls for concern. It is noteworthy that in Rivers State South-south Nigeria, Odu and Okonko [23] reported $7 \%$ L. monocytogenes in 100 pooled raw beef/pork samples. Similarly, another study in Nigeria [4] focusing on L. monocytogenes, reported its detection in raw chicken meat samples. Therefore, L. monocytogenes is not an uncommon contaminant of raw meats in Nigeria and its occurrence should not be undermined.

In this study, L. innocua predominated among isolates from beef and chicken meat samples, while unidentified Listeria species dominated in the pork samples. This suggested that no one Listeria species could be regarded as a constant predominant contaminant of raw meats marketed in the study area. Odu and Okonko [23] also reported L. innocua as the dominant isolate whereas Eruteya et al. [22] and Daniel et al. [20] stated that $L$. welshimeri and $L$. grayi dominated in their respective studies, thus further indicating that no Listeria species constantly predominates in retailed raw meats in Nigeria. However, the dominance of L. innocua in beef and chicken meats in this study may suggest that this organism, as well as other Listeria species, are readily present in environments where these meats are processed. This calls for concern because L. innocua is genetically-related to L. monocytogenes; hence, they could easily exchange virulence/resistance genes [18]. Elsewhere, L. innocua [14] or L. monocytogenes [19,32] dominated among isolates from raw poultry meat samples. In raw beef samples, L. monocytogenes [36] or L. welshimeri [19] was the most commonly isolated.

The $81.8 \%$ occurrence of L. innocua in beef in this study is higher than $11-22.5 \%$ occurrence of L. innocua in raw beef samples reported by the previous studies $[22,23,36]$. The $79.5 \%$ occurrence of $L$. innocua in chicken meat samples in this study is higher than $28.5 \%$ and $28.7 \%$ occurrence of L. innocua in raw chicken meat samples reported 
by Daniel et al. [20] and Zenaili et al. [32], respectively. However, the occurrence of L. innocua in pork samples $(47.4 \%)$ in this study is lower than $71.4 \%$ occurrence in raw pork samples reported by Odu and Okonko [22]. A 7.7\% L. grayi and 6.1\% L. ivanovii occurrences were recorded in chicken meat samples in this study whereas Abd El-Malik et al. [15] and Daniel et al. [20] reported a higher $16 \%$ and $12 \%$, and $58.3 \%$ and $11.1 \%$ occurrences of these organisms in chicken meat samples, respectively. This study observed $6.1 \%$ occurrences each of L. welshimeri, L. grayi, and L. ivanovii in beef samples. Eruteya et al. [22] reported a higher $38.9 \%$ L. grayi and $97.2 \%$ L. welshimeri occurrences, and a lower $5.6 \%$ occurrence of $L$. ivanovii occurrence in beef samples. Odu and Okonko [23] recorded $50 \%$ (higher than the results of this study) occurrences of L. grayi and L. ivanovii in beef and pork samples, respectively. In Jordan, Al-Nabulsi et al. [36] reported a lower $2.9 \% \mathrm{~L}$. welshimeri, and a higher $22.8 \%$ L. ivanovii and $8.6 \%$ L. grayi occurrences in 35 raw beef samples, respectively. The $5.1 \%$ occurrence of $L$. welshimeri in chicken meat samples in this study is similar to $5.6 \%$ occurrence of $L$. welshimeri in chicken meat samples reported by Daniel et al. [20], but it is lower than $8 \%$ occurrence of L. welshimeri in frozen raw chicken fillets reported by Abd El-Malek et al. [15].

The high resistance rates observed against PEN (100\%), RIF (72-90.9\%), CIP (60-100\%), SXT $(72-100 \%)$, and CEF $(93.9-100 \%)$, in this study indicates selection pressure. Moderate to high percentages of the isolates in this study also preferred AMP (44-57.5\%), AMX (20-50\%), GEN (36-66.7\%), TET $(40-70 \%)$, ERY (56-87.9\%), VAN (40-87.9\%), and NIT (24-70\%), further suggesting acquisition of genes encoding resistance to the agents following use-selection pressure. In Nigeria, the use of antibiotics in humans and meat-producing animals is uncontrolled and environmental sanitation is poor [13]; thus, these selection pressures might have emanated from diverse settings. The finding of high PEN and moderate to high AMP and GEN resistance in this study is worrisome because these drugs are first-line agents for treating listeriosis in humans and animals $[6,39]$. Thus, there may be limited options for therapy in individuals infected by isolates in this study. High rates of resistance against SXT, VAN, ERY, CIP, and RIF observed in this study is also disturbing because these drugs are combined and used as an alternative (second-line choice) for treating listeriosis, especially in pregnant women and patients that are allergic to $\beta$-lactams (PEN and AMP) $[2,18,36,40,41]$. Moreover, they are critically-important drugs of the highest priority for treating infections associated with Gram-positive bacteria [42]. Consumption of these resistant organisms together with the meats could result in the transfer of resistance genes by horizontal transfer to other bacteria flora in the gut of infected individuals. This could consequently jeopardize antibacterial therapy in these individuals who are potential reservoirs and disseminators of these organisms. The high rates of AMP, PEN, GEN, and TET resistance in this study are consistent with the result of the previous studies among Listeria isolates from poultry meats $[14,15,17,43,44]$, but they contrasted Gowda and Van Damme [34] stating that most Listeria isolates from raw beef carcasses were susceptible to these drugs.

A high percentage $(92-100 \%)$ of isolates in this study exhibited resistance to three or more classes of antibacterial agents tested, thus indicating that a high proportion of Listeria contaminating retailed raw meats in the study area is multidrug-resistant strains [31]. This finding is troubling because consumption of and/ or contact with these contaminated meats could result in the acquisition of multidrug-resistant Listeria strains which are capable of transferring multiple resistance genes (encoding resistance to different antimicrobial classes) to bacteria flora in the gut of infected/colonized individuals. Consequently, these carriers could subsequently discharge these organisms (through feces) into the environment thereby posing risks to public health. In Nigeria, slaughterhouse workers, meat sellers/retailers, and potential meat-buyers (during negotiation especially in general markets) frequently handle processed/ displayed raw meats. In addition, synanthropic flies often perch on these meats (which are often displayed in the open air) and thus could potentially transfer multidrug-resistant Listeria to other ecological niches. These are putative risks/routes for transmission of multidrug-resistant Listeria from these contaminated meats to buyers, consumers, and the public. VAN-resistant organisms are known to exhibit MDR [45]; interestingly, all the VAN-resistant strains in this study preferred antibacterial agents belonging to three or more classes. Moreover, MARI $>0.2$ indicates that an isolate originated from an environment with high antibacterial selection pressure [30]; thus, isolates in this study originated from high-risk sources of contamination since they all had MARI $>0.2$. This could also explain the cause of high MDR observed in this study.

\section{Conclusion}

This study has shown that a sizeable proportion of raw meats (chicken meat $27.1 \%$, pork $13.2 \%$, and beef 45.8\%) marketed in Enugu State Southeast Nigeria, is contaminated by diverse multidrug-resistant Listeria species. Thus, these meats are potential reservoirs and vehicles of transmission of multidrug-resistant Listeria and genes encoding resistance to many classes of antibacterial agents. The presence of these organisms in raw meats poses a danger to the health of handlers/consumers of these meats and the public in general. These individuals could serve as disseminators of these organisms into the environment. The spread of multidrug-resistant Listeria could have a huge impact on the ecology and epidemiology of ABR in Nigeria. Therefore, attention should be paid on the use of antibacterial agents in livestock production and 
in other settings since selection pressure in meat-yielding animals/environment could emanate from various sources. There is a need for continual monitoring of the emergence of resistant Listeria species in Nigeria because these organisms could transfer resistance genes to other clinically-relevant Gram-positive organisms. However, further studies to determine the genes encoding resistance to various antibacterial agents in the isolates are recommended.

\section{Authors' Contributions}

OJO conceptualized the study. EEU, MNI, COO, COA, ACM, and OLM collected and processed the samples. EVE and OJO analyzed the results. MUA and OJO drafted the manuscript while ROV and MV did the molecular characterization. All authors read and approved the final manuscript.

\section{Acknowledgments}

This work was funded by a grant from TETfund through the University of Nigeria (Institutional based research - IBR), TETfund grant No. TETFUND/ DESS/UNN/NSUKKA/RP/VOL.V. Fondo Nacional de Desarrollo Científico y Tecnológico FONDECYT 1161161 awarded R.Vidal.

\section{Competing Interests} interests.

The authors declare that they have no competing

\section{Publisher's Note}

Veterinary World remains neutral with regard to jurisdictional claims in published institutional affiliation.

\section{References}

1. Şanlıbaba, P., Tezel, B.U. and Çakmak, G.A. (2018) Prevalence and antibiotic resistance of Listeria monocytogenes isolated from ready-to-eat foods in Turkey. J. Food Qual., 2018: 9.

2. Olaimat, A.N., Al-Holy, M.A., Shahbaz, M., Al-Nabulsi, A.A., Abu Ghoush, M., Osaili, T.M., Ayyash, M.M. and Holley, R.A. (2018) Emergence of antibiotic resistance in Listeria monocytogenes isolated from food products: A comprehensive review. Compr. Rev. Food Sci. Food Saf., 17(2): 1277-1292.

3. Ivanek, R., Gröhn, Y.T., Tauer, L.W. and Wiedmann, M. (2004) The cost and benefit of Listeria monocytogenes food safety measures. Crit. Rev. Food Sci. Nutr., 44(7-8): 513-523.

4. Ishola, O.O., Mosugu, J.I. and Adesokan, H.K. (2016) Prevalence and antibiotic susceptibility profiles of Listeria monocytogenes contamination of chicken flocks and meat in Oyo State, south-western Nigeria: Public health implications. J. Prev. Med. Hyg., 57(3): E157-E163.

5. World Health Organization. (2018) Listeriosis South Africa. Available from: https://www.who.int/csr/don/28march-2018-listeriosis-south-africa/en. Last accessed on 15-09-2019.

6. Wu, S., Wu, Q., Zhang, J., Chen, M., Yan, Z. and Hu, H. (2015) Listeria monocytogenes prevalence and characteristics in retail raw foods in China. PLoS One, 10(8): e0136682.

7. Garedew, L., Taddese, A., Biru, T., Nigatu, S., Kebede, E., Ejo, M., Fikru, A. and Birhanu, T. (2015) Prevalence and antimicrobial susceptibility profile of Listeria species from ready-to-eat foods of animal origin in Gondar town, Ethiopia. BMC Microbiol., 15: 100.

8. The National Center for Biotechnology Information. (2018) Available from: https://www.ncbi.nlm.nih.gov/taxonomy/browser/wwwtax.cgi?id=1637. Last accessed on 13-09-2019.

9. Indrawattana, N., Nibaddhasobon, T., Sookrung, N., Chongsa-nguan, M., Tungtrongchitr, A., Makino, S., Tungyong, W. and Chaicumpa, W. (2011) Prevalence of Listeria monocytogenes in raw meats marketed in Bangkok and characterization of the isolates by phenotypic and molecular methods. J. Health Popul., 29(1): 26-38.

10. Perrin, M., Bemer, M. and Delamare, C. (2003) Fatal case of Listeria innocua bacteremia. J. Clin. Microbiol., 41(11): 5308-5309.

11. Favaro, M., Sarmati, L., Sancesario, G. and Fontana, C. (2014) First case of Listeria innocua meningitis in a patient on steroids and eternecept. J. Med. Microbiol. DOI: 10.1099/jmmcr.0.003103.

12. Troxler, R., von Graevenitz, A., Funke, G., Wiedemann, B. and Stock, I. (2000) Natural antibiotic susceptibility of Listeria species: L. grayi, L. innocua, L. ivanovii, L. monocytogenes, L. seeligeri and L. welshimeri strains. Clin. Microbiol. Infect., 6(10): 525-535.

13. Oloso, N.O., Fagbo, S., Garbati, M., Olonitola, S.O., Awosanya, E.J., Aworh, M.K., Adamu, H., Odetokun, A.I. and Fasina, F.O. (2018) Antimicrobial resistance in food animals and the environment in Nigeria: A review. Int. $J$. Env. Res. Pub. Health, 15(6): 1284.

14. Yücel, N., Çitak, S. and Önder, M. (2005) Prevalence and antibiotic resistance of Listeria species in meat products in Ankara, Turkey. Food Microbiol., 22(2-3): 241-245.

15. Abd El-Malek, A.M., Ali, S.F.H., Hassanein, R., Mohamed, A.M. and Elsayh, K.I. (2010) Occurrence of Listeria species in meat, chicken products and human stools in Assiut city, Egypt with PCR use for rapid identification of Listeria monocytogenes. Vet. World, 3(8): 353-359.

16. Pesavento, G., Ducci, B., Nieri, D., Comodo, N. and Lo Nostro, A. (2010) Prevalence and antibiotic susceptibility of Listeria spp. isolated from raw meat and retail foods. Food Contr., 21(5): 708-713.

17. Fallah, A.A., Saei-Dehkordi, S.S., Rahnama, M., Tahmasby, H. and Mahzounieh, M. (2012) Prevalence and antimicrobial resistance patterns of Listeria species isolated from poultry products marketed in Iran. Food Contr., 28(2): 327-332.

18. Arak, Z. and Ardic, M. (2017) Occurrence and antibiotic susceptibility of Listeria species in Turkey meat. Korean J. Food Sci. Anim., 35(5): 665-673.

19. Yehia, H.M., Ibraheim, S.M. and Hassanein, W.A. (2016) Prevalence of Listeria species in some foods and their rapid identification. Trop. J. Pharm. Res., 15(5): 1047-1052.

20. Daniel, S.T., Umeh, E.U. and Iheukwumere, C.C. (2015) Contamination and antibiotic susceptibility profile of Listeria species in frozen and fresh chicken sold in Makurdi, Nigeria. Int. J. Curr. Microbiol. Appl. Sci., 4(7): 617-623.

21. Adikwu, P., Umeh, E.U., Azua, E.T. and Obande, G.A. (2016) Prevalence and antimicrobial susceptibility of Listeria monocytogenes isolated from beef, pork and chicken sold in Makurdi metropolis. Br. Microbiol. Res. J., 14(5): 1-7.

22. Eruteya, O.C., Odunfa, S.A. and Lahor, J. (2014) Listeria spp. in raw cow and goat meat in Port Harcourt, Nigeria. Br. Biotechnol. J., 4(2): 204-214.

23. Odu, N.N. and Okonko, I.O. (2017) Prevalence and antibiotic susceptibility of Listeria monocytogenes in retailed meats in Port Harcourt metropolis, Nigeria. Pub. Health Res., 7(4): 91-99.

24. Ebakota, D.O., Abiodun, O.A. and Nosa, O.O. (2018) Prevalence of antibiotics resistant Listeria monocytogenes strains in Nigerian ready-to-eat foods. Food Saft., 6(3): 118-125. 
25. International Organization for Standardization. (1996) ISO 11290-1, Microbiology of Food and Animal Feeding Stuffs. Horizontal Method for the Detection and Enumeration of Listeria monocytogenes. International Organization for Standardization, Geneva.

26. Doumith, M., Buchrieser, C., Glaser, P., Jacquet, C. and Martin, P. (2004) Differentiation of the major Listeria monocytogenes serovars by multiplex PCR. J. Clin. Microbiol., 42(8): 3819-3822.

27. Clinical and Laboratory Standards Institute. (2018a) Methods for Dilution Antimicrobial Susceptibility Tests for Bacteria that Grow Aerobically. $11^{\text {th }}$ ed. CLSI Standard M07. Clinical and Laboratory Standards Institute, Wayne, PA.

28. European Union Committee on Antimicrobial Susceptibility Testing. (2018) Breakpoint Tables for Interpretation of Zone Diameters and MICs, Version 8.1. Available from: http:// www.eucast.org. Last accessed on 10-09-2019.

29. Clinical and Laboratory Standards Institute. (2018b) Performance Standard for Antimicrobial Susceptibility Testing. CLSI Standard M100. 28 $8^{\text {th }}$ ed. Clinical and Laboratory Standards Institute, Wayne, PA.

30. Krumperman, P.H. (1983) Multiple antibiotic resistance indexing of Escherichia coli to identify high-risk sources of fecal contamination of foods. Appl. Env. Microbiol., 46(1): 165-170.

31. Magiorakos, A.P., Srinivasan, A., Carey, R.B., Carmeli, Y., Falagas, M.E., Giske, C.G., Harbarth, S., Hindler, J.F., Kahlmeter, G., Olsson-Liljequist, B., Paterson, D.L., Rice, L.B., Stelling, J., Struelens, M.J., Vatopoulos, A., Weber, J.T. and Monnet, D.L. (2012) Multidrug-resistant, extensively drug-resistant and pandrug-resistant bacteria: An international expert proposal for interim standard definitions for acquired resistance. Clin. Microbiol. Infect., 18(3): 268.

32. Zeinali, T., Jamshidi, A., Bassami, M. and Rad, M. (2017) Isolation and identification of Listeria spp. in chicken carcasses marketed in northeast of Iran. Int. Food Res. J., 24(2): 881-887.

33. Osaili, T.M., Alaboudi, A.R. and Nesiar, E.A. (2011) Prevalence of Listeria spp. and antibiotic susceptibility of Listeria monocytogenes isolated from raw chicken and ready-to-eat chicken products in Jordan. Food Contr., 22(3-4): 586-590.

34. Gowda, T.K.G. and Van Damme, I. (2017) Occurrence and antibiotic susceptibility of Listeria species and Staphylococcus aureus in cattle slaughterhouses of Kerala, South India. Foodborne Pathog. Dis., 14(10): 573-579.
35. Caplan, M.E., Mateescu, L.A., Dimov, T.V., Rafila A. and Borcan, A.M. (2014) Antibiotic susceptibility profiles of Listeria monocytogenes strains isolated from food products and clinical samples. Rev. Română Med. Lab., 22(2): 255-262.

36. Al-Nabulsi, A.A., Osailia, T.M., Awada, A.A., Olaimat, A.N., Shakera, R.R. and Holley, A. (2015) Occurrence and antibiotic susceptibility of Listeria monocytogenes isolated from raw and processed meat products in Amman, Jordan. J. Food, 13(3): 346-352.

37. Guillet, C., Join-Lambert, O., Le Monnier, A., Leclercq, A., Mechaï, F. and Mamzer-Bruneel, M.F. (2010) Human listeriosis caused by Listeria ivanovii. Emerg. Infect. Dis., 16(1): 36-38.

38. Beye, M., Gouriet, F., Michelle, C., Casalta, J.P., Habib, G., Raoult, D., Fournier, P.E. (2016) Genome analysis of Listeria ivanovii strain G770 that caused a deadly aortic prosthesis infection. N. Microbol. N. Infect., 10: 87-92.

39. Charpentier, E. and Courvalin, P. (1999), Antibiotic resistance in Listeria spp. Antimicrob. Agents Chemother. 43(9): 2103-2108.

40. Hof, H. (2004), An update on the medical management of listeriosis. Expert Opin. Pharmacother., 5(8): 1727-1735.

41. Conter, M., Paludi, D., Zanardi, E., Ghidini, S., Vergara, A. and Ianieri, A. (2009) Characterization of antimicrobial resistance of foodborne Listeria monocytogenes. Int. J. Food Microbiol., 128(3): 497-500.

42. World Health Organization. (2017) Critically Important Antimicrobials for Human Medicine. $5^{\text {th }}$ ed. Available from: http://www.apps.who.int/iris/bitstream/handle/106 65/255027/9789241512220-eng.pdf;jsessionid=E6465D3C02939652305588FF323F0210? sequence $=1 ; 2017$. Last accessed on 10-09-2019.

43. Ormanci, F.S.B., Erol, I., Ayaz, N.D., Iseri, O. and Sariguzel, D. (2008) Immunomagnetic separation and PCR detection of Listeria monocytogenes in turkey meat and antibiotic resistance of the isolates. Br. Poult. Sci., 49(5): 560-565.

44. Ayaz, N.D. and Erol, I. (2010) Relation between serotype distribution and antibiotic resistance profiles of Listeria monocytogenes isolated from ground turkey. J. Food Prot., 73(5): 967-972.

45. Munita, J.M., Bayer, A.S. and Arias, C.A. (2015) Evolving resistance among Gram-positive pathogens. Clin. Infect. Dis., 61(S2): S48-S57.

\section{$* * * * * * * *$}

